\title{
LABOUR MARKET PARTICIPATION: THE IMPACT OF SOCIAL BENEFITS IN THE CZECH REPUBLIC AND SELECTED EUROPEAN COUNTRIES
}

\author{
Kamila Fialová, Martina Mysíková*
}

\begin{abstract}
:
This paper aims to quantify the impact of social benefits on labour market participation in the Czech Republic and provides a comparison with selected European countries. It applies the logistic regression to estimate the probability of labour market participation depending on social benefits related to net wage of the individuals, controlling for individual and household characteristics. Our results indicate that the work disincentives via social benefits do exist in most of the included countries and they proved to be relatively strong in the Czech Republic. When trying to understand the reasons for recently decreasing participation rate in the Czech Republic, the often called "generous" Czech social benefit system appears to be relevant.
\end{abstract}

Keywords: inactivity trap, labour market participation, social benefits

JEL classification: I38, J21

\section{Introduction}

The aggregate participation rate was gradually increasing in the EU- 25 from $68.7 \%$ in 2000 to $70.5 \%$ in 2006 as well as both the male (from $77.4 \%$ to $78.0 \%$ ) and the female (from $60.0 \%$ to $63.1 \%$ ) participation rates (European Commission, 2007). This trend appears not to be followed by the Czech Republic where the aggregate participation rate was continuously decreasing from $71.3 \%$ to $70.3 \%$ in the same period with the male rate falling from $79.1 \%$ to $78.3 \%$ and the female rate from $63.6 \%$ to $62.3 \%$

Social benefits can create substantial disincentives to labour market participation. If we try to achieve higher participation rate, such disincentives should be eliminated in order to "make work pay". The Czech Republic has experienced reforms in social

* Kamila Fialová, Institute of Economic Studies, Charles University in Prague, and Komerční banka, Prague (kfialova@email.cz); Martina Mysíková, Institute of Economic Studies, Charles University in Prague, and Institute of Sociology of the Academy of Sciences, Prague (martina.mysikova@centrum.cz). This paper was written with the support of the Grant Agency of Charles University, Grant No. 2199/2007 ("Analysis of the Impact of the Selected Social Policy Instruments on the Czech Labour Market and a Broad International Comparison") and of the Grant Agency of the Czech Republic, Grant No. 403/08/1369 ("Individuals and Households in the Czech Republic: Transformation Changes and Cross-National Comparison”). The authors wish to thank Martin Kubíček (Institute of Economic Studies, Charles University in Prague) for his valuable advices to solving the logistic regression models. The usual disclaimer applies. 
security system recently with its first phase already starting from 2008. The main goal of these reforms is to spur the labour market participation by lowering the income redistribution. ${ }^{1}$ In this context, this paper is concerned with the impact of social benefits on decision about labour market participation in the Czech Republic and the real potential of social reform measures in stimulating labour market participation.

The share of social income in total gross income has rather increased recently in the Czech Republic, therefore, the social benefits level could be a relevant factor when considering the decreasing labour market participation in the Czech Republic over the last years. The share of social income amounted to $9.8 \%$ of the total gross income in households where the head of the household was an employee in 2004, with even slight decrease to $9.4 \%$ in 2005 . However, this share rose from $54.3 \%$ to $55.4 \%$ in households of unemployed and from $36.0 \%$ to $40.2 \%$ in households of (not retired) inactive persons as a head of the household between these two years (Czech Statistical Office 2007a-b). Therefore, social benefits can create substantial incentives to withdraw from the labour market.

Using the most recent data from the Statistics on Income and Living Conditions database this paper aims to find out whether the social benefit level influences the participation on the labour market. More precisely, it estimates the probability of labour market participation of individuals depending on the social benefits they received in the previous year related to their net wage. Consequently, it tries to reveal whether the social security reforms can affect the participation decision in the Czech Republic.

This paper offers an econometric analysis of labour market participation - using the microeconomic data - which controls for social benefits related to wage, family structure and other variables. Its aim is to reveal how the probability of labour market participation differs depending on the relative level of social benefits in the Czech labour market, running the regression model for all individuals as well as for women separately. Subsequently, an international comparison is provided.

The paper is organized as follows: The next section provides a literature overview and outlines the importance of the selected topic. Section 3 depicts the methodology for the participation equation estimations. It also describes the EU-SILC data to which the present paper is to be applied and variables used in the model. Section 4 presents the results, also separately for women, in the Czech Republic as well as in selected EU countries. The main results and discussion are summarized in Section 5.

\section{Literature Overview and Motivation}

It is often argued that the interaction of tax and benefit systems may cause problems both on demand and supply side of the labour market (see, e.g., Immervoll and O'Donoghue, 2003; OECD, 1997). In particular, generous out-of-work income can create significant disincentives to search well-paid work or to stay at work. These disincentives were often assumed to be one of the main causes of sluggish economic growth and relatively high unemployment in the Europe at the end of last century (European Commission, 2000).

1 The total amount of redistributed income was supposed to be lowered by more than CZK 8 billion during 2008 (Ministry of Labour and Social Affairs). 
Generally, social protection policies have been traditionally focused particularly on old age, short-term unemployment and disability. Several crucial factors influenced the social protection regimes in the past decade. First, increasing long-term unemployment led to longer unemployment benefits claims and greater dependence on social assistance as the unemployment benefits are often time-limited. ${ }^{2}$ Second, the family structure changed over time; there are more single-parent families, more households of individuals living alone etc., which are threatened by poverty more likely and are, therefore, more dependent on social assistance. ${ }^{3}$

The study of the European Commission (2004) points out that the so-called working age benefit dependency ratio recorded significant changes in the EU member states during the 1990s. ${ }^{4}$ The benefit dependency ratio expresses the number of persons receiving a social security benefit in relation to the number of persons in employment. ${ }^{5}$ Considering only the unemployment benefits and social assistance, the ratio rose until 1993 and declined thereafter in the majority of covered countries. Generally, the benefit dependency is higher among women than among men although the difference decreased over the 1990s.

The social benefit system (together with the tax system ) involves the trade-off between equity and efficiency targets. Work dis/incentives can be captured by various measures. The out-of-work income relative to in-work income, measured by the replacement rates as a proxy for benefit generosity (e.g., OECD, 2002), affects the decision to participate on the labour market. If the replacement rate is too high that work "does not pay", it can result in the so-called unemployment trap (see e.g., Carone and Salomäki, 2001; Snower, 1997).

OECD (2002) study compares the net replacements rates (NRR) across the member countries. ${ }^{6}$ It provides the net replacement rates for several types of households of various unemployment duration, considering the available level of social benefits and the average production worker salary. NRR for persons in the initial period of unemployment with not working spouse and two children was $70 \%$ in the Czech Republic whilst the values ranged from $44 \%$ in Greece to $91 \%$ in Canada and Switzerland. This figure was $80 \%$ for long-term unemployed who do not receive any

2 For example, the long-term unemployment as a percentage of labour force rose from 2.0 in 1998 to 4.2 in 2005 in the Czech Republic, which was one of the highest values in the EU (European Commission, 2006).

$34.3 \%$ of all households were single-parent households with dependent children and $22.8 \%$ were households of individuals in the Czech Republic in 2005 (Czech Statistical Office, 2007a). The at-risk-of-poverty rate (share of persons under poverty threshold, which is $6 \%$ of median of national equivalised disposable income) for persons living in single-parent households was $41.0 \%$ and $16.4 \%$ for one-person households in 2005 in the Czech Republic, while this index was 10.4\% on average (Czech Statistical Office, 2007a).

4 This study included Austria, Belgium, Denmark, France, Germany, the Great Britain, the Netherlands, Spain and Sweden.

5 More precisely, the benefit years of persons aged 15 to 65 to the total number of labour years (all persons aged 15 or older, in full-time equivalents).

6 Net replacement rate is calculated as a share of household out-of-work income and net in-work income, where the out-of-work income consists of housing benefits, family and children benefits added to unemployment insurance for short-term unemployed and to social assistance for long-term unemployed. 
unemployment benefits in the Czech Republic with the values ranging from $10 \%$ in Greece to $87 \%$ in Iceland.

This suggests that long-term unemployed average production workers were less motivated to start to work than people in the initial phase of unemployment in the Czech Republic. The social benefits recipients might lose their motivation to search a job and to move from unemployment into employment. Moreover, they can be encouraged to rely fully on the social system and/or withdraw entirely from the labour market. This effect can influence especially the low-wage workers. Not entering the labour market can be in their interest since the earned income could differ only moderately from their out-of-work income. Theoretically, the higher the provided allowances, the lower are incentives to enter the labour market.

Another indicator which can be used to measure the extent to which benefits and taxes decrease the motivation to start to work is the marginal effective tax rate (METR). This measure describes the share of additional income which is taxed away when moving to employment. ${ }^{7}$ Carone et al. (2004) argue that the METR for an unemployed average production worker with not employed spouse returning to the same wage-level job was $77 \%$ in 2001 in the Czech Republic (ranging from 61\% in Hungary to 96\% in Slovakia).

Beside the unemployment trap, we can distinguish the so-called inactivity trap which applies to people not receiving any unemployment benefits, who are out of the labour force or "inactive" in sense of paid employment. Inactive individuals who would like to (re)enter the labour market face up work disincentives resulting from tax benefit systems so that they often decide to stay out of the labour force. Minimum income and various benefits, which would be lost when taking up a paid job, can be one of the reasons for non-participation.

The inactivity trap can be measured by METR for inactive people. According to Carone et al. (2004) study, the METR for an inactive person with not employed spouse and two children starting to work with average production salary amounted to $77 \%$ in 2001 in the Czech Republic (ranging from 12\% in Italy to $96 \%$ in Slovakia). Therefore, this suggests that the social benefits for an inactive couple with two children were relatively high, such that a movement to employment leaved the family with only $23 \%$ of the additional income. The METR was significantly lower for example for similar family without children $(64 \%)$. Therefore, the benefits related to children might play a significant role. The decision to participate on the labour market could be also highly influenced by the family structure and economic status of the spouse.

Based on the tax-benefit system in the Czech Republic in 2002, the OECD (2004) study argues that the work disincentives were created mainly to families with children, single parent families and also childless unemployed couples, while single persons and persons with employed spouse did not face such significant disincentives to take up a job. ${ }^{8}$

$7 \quad$ METR $=1-\Delta y_{\text {net }} / \Delta y_{\text {gross }}$, where the change in income corresponds to the additional income from moving to employment. This measure can be used to capture the unemployment trap (the additional income stems from moving from unemployment to employment), inactivity trap (the additional income comes from moving from inactivity to employment) and poverty trap (the additional income is related to increasing the number of hours worked for those already in low-paid work).

8 Another point is that the state social support is not conditioned by active looking for a job so that many beneficiaries stay on benefits for long periods, often ensuring income by working in the grey economy. Renoy at al. (2004) argue that housewives and registered unemployed create one of the main groups of undeclared workers. 
The inactivity trap affects particularly women, whose labour supply is more elastic than men's, as shown, for example, by the study of Jaumotte (2003). It argues that, based on the data from 2001, the share of inactive women who would like to have a work is $12 \%$ on average in 19 European countries, with a higher share among women in primeworking age, middle and higher education levels and, especially, among women who do not seek a job due to family commitments. Jaumotte (2003) applied an econometric analysis using macroeconomic data to determine the impact of relevant policies on female participation rates in several countries: social security system and child care subsidies were especially relevant.

The above discussed studies consider "average" representative worker or family or are based on macroeconomic level, as well as most of the studies concerning the impacts of social benefit system on the labor market. As opposed to such studies, the present paper aims to examine the impact of social benefits on microeconomic level. We relate the (net) social benefits received in the previous year to net wages of the individuals and estimate their impact on labour market participation controlling for family circumstances. The analysis is conducted jointly for both sexes and also separately for women. Our assumption, based on existing literature, is that the higher the benefit-wage ratio the lower we would expect the probability of labour market participation. In other words, the higher the benefit-wage ratio the more likely the individuals will be inactive in the subsequent period.

\section{Methodology and Data}

The purpose of this study is to assess the relationship between social benefits and wages and its impact on participation decision. Section 3.1 depicts the approach and methodology applied in this paper. The following section describes the data and Section 3.3 explains the variables used to estimate the impact on participation decision and formulates the equation used in the logistic regression for participation.

\subsection{Methodology}

When individuals decide about their labour market participation, they consider whether the work does pay. We assume that individuals compare the (net) social benefits received to their potential net wage. Therefore, social benefits relative to wage are supposed to influence the labour market participation decision rather than social benefits and wages absolute levels.

Majority of the social benefits are derived from the individual or household income of the previous year, hence, the individual only one year later finds out whether the work does pay. Since the data used in this paper covers only one-year income data (we call this period $t$ ), supplemented by the information on economic activity during the corresponding period, it is impossible to follow the economic activity during the previous year $(t-1)$, which would enable to assess the labour market participation decision more precisely. Besides, it includes the current economic activity status $(t+1)$ which is several months lagged to the income reference period $(t)$.

We accept the assumption that individuals compare their actual social benefit level in period $t$ (which mostly depends on last year's income, i.e. in period $t$ - 1 , of the whole 
household and therefore on the economic activity of all household members) to their "usual" net wage. For those who were employed during the income reference year $(t)$, we apply their average monthly net wage. For inactive people, we estimate their potential net wage using the Heckman regression model (Heckman 1979, for another example of applied Heckman's model, see, e.g., Beblo et al. 2003) in order to avoid the possible bias of estimated wages. This model was suggested in order to eliminate the selection bias which could occur when working individuals do not create a random subsample of the population but differ systematically from non-participating individuals. ${ }^{9}$ The results of Heckman procedure are reported in Appendix 1.

In our framework, the participation decision in the next period $(t+l)$ is then influenced by individuals' relative social benefits, measured as a share of the social benefits in period $t$ to usual net wage. If the ratio is sufficiently high, the work could not pay and the individuals could decide not to participate on the labour market.

This assumption is rather strong since we are not able to prove that individuals decide about the labour market participation in such a short period. Moreover, some individuals might receive an income from grey economy and thus social benefits might influence their labour market participation to a lesser extent. We are aware that we cannot draw conclusions without the knowledge of long-term pattern of economic behavior of individuals. However, the ambition of this paper is not to predict the level of social benefits at which the individuals would decide to take a job or leave the labour market, but rather to show whether there exists some causality between the relative social benefits received in one year and labour market participation in the subsequent year. Due to data limitations we provide a platform for further research on oncoming longitudinal data.

The social benefits covered in the present paper include family and children allowances, housing allowances and all other benefits related to social exclusion, equivalised to the number of household members. Finally, the ratio of (net) social benefits and net usual wage is included into the regressors of the participation model, controlling also for other variables influencing the labour market participation (household composition, presence of the spouse and her/his economic activity etc.).

\subsection{Data Description}

This study is based on EU-SILC 2005 data. The household survey EU-SILC ${ }^{10}$ is a panel survey which replaced the ECHP ${ }^{11}$ in 2004. It is a harmonized survey compulsory for all the EU member states, and thus providing reliable data for a possible crosscountry comparison. The information is collected on a household level (mainly information on living conditions) and also on an individual level (e.g. individual and job characteristics, wages, income, social allowances). Reference period for income variables is the year 2004 (period $t$ ); the majority of other variables is related to the

9 For more detailed discussion of appropriateness of the Heckman model, see, e.g. Mysíková (2007).

10 EU-SILC (European Union - Statistics on Income and Living Conditions) is the so called four-year rotational panel, which means that information is being collected for four years about a number of households, out of which $1 / 4$ is dropped and a correspondent number randomly added each year. The data will consist of cross-sectional as well as longitudinal components in the following years.

11 European Community Household Panel. 
current situation (period $t+1$ ), which means the time of the survey (the second quarter 2005 in case of the Czech Republic).

The Czech data includes 10,333 individuals (8,628 aged 16 and over) in 4,351 households. In this study, individuals aged 16 to 64 years old are considered only. In order to avoid the ambiguity of participation decision, individuals in retirement, students, disabled and people in compulsory military community are excluded as their choice of economic activity is limited. Further, self-employed are eliminated since their income contains irregularities which would make the analysis biased. Part-time employees are excluded since their monthly income is incomparable with full-time workers' wage. ${ }^{12}$ Finally, unemployed were also excluded since the information on their unemployment status is self-reported and hence rather ambiguous. ${ }^{13}$

In other words, individuals who moved between full-time employment and inactivity during the survey reference period are included. This leaves us with 3,322 individuals, 3,107 of them do participate on the labour market and 215 do not. ${ }^{14}$ The female sub-sample consists of 1,579 individuals. The data provides us with yearly net wages, therefore, the net monthly earned income was constructed according to the number of worked months. Individual weights which reflect the number of people in the whole population who are represented by a particular individual were included. ${ }^{15}$

\subsection{The Model and Variables Description}

The logistic regression is used for computations since the explained variable in the applied model is dichotomous. This variable is the participation on the labour market, which takes the value of 1 if the individual participates and 0 if she/he is out of the labour force in the current reference period $t+1$ (second quarter 2005, i.e. 4 to 6 months lagged to the income reference period $t$ ).

The logistic model takes the following form:

$$
\ln [p /(1-p)]=\beta_{0}+\beta_{i} X_{i}
$$

where $p$ is the probability of participation on the labour market in period $t+1$ and vector includes all explanatory variables. The explanatory variables included in equation (1)

12 The exclusion of part-time workers represents a negligible number of workers since part-time employment is very low in the Czech Republic.

13 From participation decision point of view, the unemployed people are participating in the labour market. But is hard to distinguish whether a self-reported unemployment status means that the individual is not able to find a job or whether she/he lacks the effort to find a job and therefore her/his economic status is rather "inactive". Another reason for excluding the unemployed is that the unemployment benefits reported in the data set lacks the information on number of months of the claim, which could bias the estimates. Moreover, the unemployment benefits are rather of different nature than the social benefits - the first serve as a time-limited compensation for lost wage while the second should compensate lasting weak social conditions. Moreover, we excluded those who have never worked since their job characteristics are missing and those whose monthly wage was lower than legal minimum wage and/or who received sickness benefits since their wages were biased.

14 Based on the data sample, a representative not participating individual is a woman aged 45 or less with secondary education living with employed partner and at least one dependent child.

15 The descriptive summary for compared European countries is stated in Appendix 2. 
are the benefit-wage ratio, age, education, sex, presence of working and not working partner, presence of children and region as a proxy for the unemployment rate.

The benefit-wage ratio $\left(B E N \_W A G E j\right)$ is the share of the equivalised monthly social benefits received in the income reference period $t$, i.e. the previous calendar year 2004 , to the "usual" net monthly wage. Since $B E N \_W A G E j$ is a continuous variable it was divided into several intervals in order to construct the dummy variables reaching 1 if the individual benefit-wage ratio belongs to the particular interval, and 0 otherwise. ${ }^{16}$

$A G E k$ are dummies for age reflecting also the work experience ( $A G E \_30$, $\left.A G E 31 \_45, A G E 46 \_55\right)$. The education variables (SEC_EDUC and TER_EDUC correspond to secondary and tertiary education. $S E X$ is a dummy variable which equals 1 when the individual is male. EM_PART and NEM_PART are dummies for the presence of employed partner and not employed partner in the household, respectively. The counterpart to these two variables is living without any partner. CHILDO_2, CHILD3_5 and CHILD6_15 are dummies for the presence of children aged 0 to $2, \overline{3}$ to 5 and 6 to 15 years, respectively.

$R E G l$ are dummies for region as a proxy for unemployment levels. The regions on NUTS2 level were clustered into several groups according to the unemployment and long-term unemployment rates. The unemployment rate in region is supposed to have some effect on labor market participation via "discouraged worker effect" although the evidence of this effect is rather ambiguous (see, e.g. Sandmeyer and Warner 1970, Schweitzer and Smith 1974).

\section{Results}

The first sub-section provides the results of the participation model for the Czech Republic, while the second compares the results for selected European countries (Slovakia, Poland, Hungary, Italy, Spain and Greece), using the same EU-SILC database and the same above described methodology. The Appendix 2 states the descriptive summary of the countries' samples.

\subsection{The Czech Republic}

The Czech results for both sexes (model (1)) are reported in Table 1, Table 2 then shows the results separately for women (model (2)). Both the models appeared to be robust - Gini coefficient (cumulative accuracy ratio) amounts to 85.1 for the total model (1) and 92.1 for the female model (2), Kolmogorov-Smirnov test to 78.5 for the total model (1) and 81.5 for the female model (2). Another widely used measure of the

16 Initially, the sample was divided into 20 groups each containing 5 percentiles according to the benefit-wage ratio level. In case that the share of not participating individuals was similar in any two adjacent groups, these groups were merged into one interval. The purpose is to divide the sample in several groups according to the benefit-wage ratio, where the participating and not participating individuals are represented more equally across the groups. If the share of not participating individuals tends to increase or decrease across the groups, the variable is supposed to have some influence on the explained variable. Transforming the continuous variable into dummy variables is a standard method in applied logistic regression (e.g. Hosmer and Lemeshow, 2000). The final dummies are described in Appendix 2. 
overall fit of models is to examine its ability to correctly classify observations. This figure shows $97.6 \%$ correctness for the total model and $95.4 \%$ for the female model. ${ }^{17}$

The two highest intervals of the wage-benefit ratio, which cover the highest decile, proved to be significant in model (1) and affirm the expectations that higher values of social benefits do negatively affect the subsequent labor market participation. The lowest benefit-wage ratio was omitted from the model due to collinearity. Therefore, the probabilities of participation resulting from the model have to be considered in relation to the reference variable, which is here represented by this lowest ratio (i.e., the benefits amounting to less than $13 \%$ of the net wage). The odds ratio of the reference variable equals 1 .

Table 1

Participation Model - Total - CZ

\begin{tabular}{|l|c|c|c|}
\hline \multirow{2}{*}{} & \multicolumn{3}{|c|}{ Model (1) - total } \\
\cline { 2 - 4 } & coeff. & s.e. & odds ratio \\
\hline BEN_WAGE2 (13 to 19\%) & $-2.108^{* * *}$ & $(0.307)$ & 0.121 \\
\hline BEN_WAGE3 (19 to 77\%) & $-3.113^{* * *}$ & $(0.310)$ & 0.044 \\
\hline SEX & $2.892 * * *$ & $(0.394)$ & 18.025 \\
\hline EM_PART & $-0.533^{*}$ & $(0.288)$ & 0.587 \\
\hline NEM_PART & $0.810^{*}$ & $(0.462)$ & 2.247 \\
\hline CHILD0_2 & $-2.699 * * *$ & $(0.274)$ & 0.067 \\
\hline CHILD3_5 & $-1.123 * * *$ & $(0.273)$ & 0.325 \\
\hline CONSTANT & $3.960 * * *$ & $(0.273)$ & - \\
\hline
\end{tabular}

Notes: * significance at the $10 \%$ level, ${ }^{* *}$ significance at the $5 \%$ level, ${ }^{* * *}$ significance at the $1 \%$ level. Standard errors in parentheses.

Correctness of observation classification $97.6 \%$, cumulative accuracy ratio 85.1 , K-S test 78.5.

Source: Own calculations based on EU-SILC data.

The benefit-wage ratio ranging from 13 to $19 \%$ (BEN_WAGE2) decreases the participation probability substantially - the odds ratio stands at 0.12 . Finally, if the benefits comprise 19-77\% (BEN_WAGE3) of the net wage, the odds ratio further decreases to 0.04 . This means that if we compare two individuals, first one who received zero or very small social benefits related to her/his wage, and second who obtained social benefits that amounted to $20-77 \%$ of her/his wage, the second one would be 0.04 times as likely to participate compared to the first one.

The other, controlling, variables do not show surprising results - men are more likely to participate in the labour market; the presence of employed spouse in the household decreases the probability whilst the presence of not employed spouse increases the participation probability (compared to individuals living without any spouse); the presence of children aged less than six years lowers the probability of participation - the younger the children the lower the probability.

Similarly, the female model (Table 2) proved the three highest benefit-wage ratios to be significant; these intervals cover the highest 15 percentiles. The share of

17 The cut value is 0.5 . 
benefits amounting to $7-16 \%\left(B E N \_W A G E 2\right.$ to $\left.B E N \_W A G E 3\right)$ of the net wage refers to relatively low participation probability - odds ratio ranging from 0.31 to 0.12 . The highest benefit-wage ratio ( $B E N$ WAGE4) covers a wide range of the ratios of the benefits to the net wage -16 to $75 \%$. The probability of labour market participation then falls even more - the odds ratio declines to 0.04 .

As opposed to the model (1), the female model proved the presence of employed and not employed spouse in the household to be insignificant. This suggested that women's decision about labour market participation is less sensitive to the economic activity of the spouse than men's (more precisely, less than when total sample is considered). The dummies EM_PART and NEM_PART were merged into one variable PARTNER, which was significant and confirmed a negative effect on female labour market participation.

Table 2

Participation Model - Female - CZ

\begin{tabular}{|l|c|c|c|}
\hline \multirow{2}{*}{} & \multicolumn{3}{|c|}{ Model (2) - female } \\
\cline { 2 - 4 } & Coeff. & s.e. & odds ratio \\
\hline BEN_WAGE2 (7 to 11\%) & $-1.173^{* *}$ & $(0.505)$ & 0.309 \\
\hline BEN_WAGE3 (11 to 16\%) & $-2.104^{* * *}$ & $(0.405)$ & 0.122 \\
\hline BEN_WAGE4 (16 to 75\%) & $-3.225^{* * *}$ & $(0.327)$ & 0.040 \\
\hline PARTNER & $-0.574^{*}$ & $(0.322)$ & 0.563 \\
\hline CHILD0_2 & $-3.443^{* * *}$ & $(0.329)$ & 0.032 \\
\hline CHILD3_5 & $-1.229^{* * *}$ & $(0.327)$ & 0.292 \\
\hline CONSTANT & $4.555^{* * *}$ & $(0.330)$ & - \\
\hline
\end{tabular}

Notes: * significance at the $10 \%$ level, ${ }^{* *}$ significance at the $5 \%$ level, ${ }^{* * *}$ significance at the $1 \%$ level. Standard errors in parentheses.

Correctness of observation classification $95.4 \%$, cumulative accuracy ratio 92.1 , K-S test 81.5 .

Source: Own calculations based on EU-SILC data.

The coefficients of the variables referring to the presence of children confirm an intuitive supposition that women with preschool-aged children (CHILDO_2 and CHILD3_5) stay at home and only (re)enter the labour market when their children reach school age. The presence of older children (CHILD6_15) proved insignificant in both models.

\subsection{Selected European Countries}

Six countries where the participation rate was even lower than in the Czech Republic were selected for comparison - Slovakia, Poland, Hungary, Italy, Spain and Greece. ${ }^{18}$

18 We chose the countries with low participation rates since a sufficient share of not participating individuals is required for the logistic regression purposes. As retired, students and disabled were excluded from our sample, the participation rate in our sample is much higher than in the official statistics and, hence, the share of not participating individuals could be insufficient for fitting the regression model. Moreover, the analysis of the determinants of participation is more relevant and contributive for countries facing problems of low labor market participation. 
Despite the EU-SILC survey being harmonized on the European level, there still exist slight differences in the data. The information on region is missing in Slovakia. On the other hand, more detailed classification of regions (NUTS3) is available in Spain. In Hungary, gross wages as well as gross social benefits were only stated, therefore, possible bias has to be taken into account. The detailed model results are presented in Appendix 3.

Although the total participation rate in Slovakia (68.9\%) was even lower than in the Czech Republic (70.4\%) in 2005 (European Commission, 2007), the share of not participating individuals in the data sample is much lower. Therefore, the regression was only carried out for the female sub-sample. Even so, not participating individuals create $5.1 \%$ in the female sub-sample, hence the results have to be treated with caution.

The two highest intervals of the benefit-wage ratio, which cover the highest decile, proved to be significant in the Slovak female model and affirm the expectations that the higher values of social benefits lower the probability of labour market participation. If the share of the benefits amounts to $22-58 \%$ of the net wage (BEN_WAGE3), the odds ratio falls to 0.22 .

In the Polish sample, approximately $30 \%$ of the individuals received some social benefits. Both the benefit-wage ratios included in the total model were significant. The results confirm the expectations - the higher the interval of benefit-wage ratio, the lower the probability of labour market participation. If the share of the benefits amounts to $11-96 \%$ of the net wage (BEN_WAGE3), which represents the highest 5 percentiles, the odds ratio stands at 0.27 . The results for the female sub-sample are even stronger: the odds ratio for the highest benefit-wage ratio, where the benefits amount to $13-96 \%$ of the net wage, is 0.17 .

In Hungary, all the benefit-wage ratio variables included in both models proved to be significant, but the models do not fit well, are very sensitive to included controlling variables and also the share of not participating individuals in the sample is very low (approximately 5\%). The results do not confirm the expectations for the female sub-sample. The interpretation of the results is rather ambiguous since in the female model the probability of participation for the lowest benefit-wage ratio is higher than for the middle benefit-wage ratio, and lower than for the highest benefit-wage ratio. Therefore, the female participation as a function of benefit-wage ratio would be V-shaped which lacks any theoretical basis and makes the interpretation impossible. We might conclude that social benefits did not have any straightforward effect on labor market participation in Hungary. Moreover, the Hungarian data provides only gross components of the benefit-wage ratio which might bias the results.

The results of both Italian models confirm the expectations that higher benefitwage ratios lower the probability of labor market participation; the effect is stronger in the female model. The probabilities of participation are rather high compared to the other included countries - the odds ratios of the highest benefit-wage ratios, covering the highest 5 percentiles in both models, amount to 0.61 in the total model and 0.51 in the female model. This is not surprising since the average benefit-wage ratio of individuals who received any social benefits in Italy is the lowest among included countries.

The share of individuals who received some social benefits is very low in the Spanish sample $-4.9 \%$ in the total sample and $4.8 \%$ in the female sub-sample. Hence, only a single interval of the benefit-wage ratio was constructed. Thus, the dummy 
variable of benefit-wage ratio takes the value 1 if the ratio is positive, and 0 otherwise. The positive benefit-wage ratio shows higher probability of labour market participation than zero benefit-wage ratio in both total and female models, i.e., the opposite of the expected result. However, the low share of positive benefit-wage ratios in both samples makes the results less reliable (see the Appendix 2).

In Greece, only $11.2 \%$ of the individuals (in both total and female samples) received some social benefits. When the share of the benefits amounts to $5-57 \%$ of the net wage in the total model, which represents the highest 5 percentiles, the odds ratio stands at 0.66 . The effect is stronger in the female model where the benefit-wage ratio (share of the benefits amounting to $6-57 \%$ of the net wage) corresponds to even lower odds ratio (0.55). Therefore, the negative impact of social benefits on the probability of labour market participation is rather small in Greece.

\section{Conclusion}

This paper investigated the impact of social benefits on labour market participation in the Czech Republic and compared the results with selected European countries. The social benefits relative to the net wage of the individuals proved to be relevant to the probability of participation in the Czech Republic. The individuals whose social benefits comprised $19-77 \%$ of the net wage in 2004 are 0.044 times likely to participate in the labour market in the subsequent year than those with the very low benefit-wage ratios. This effect is only slightly stronger in case of women, where the individuals with share of social benefits ranging from 16 to $75 \%$ of the net wage are moderately less likely to participate in the labour market (0.040).

The aim of this paper was not to predict the level of social benefits at which the work does pay, at which individuals start to work or leave the labour market, but rather to state whether there exists some relationship between social benefits obtained during one year and subsequent labour market participation. Therefore, despite the assumptions of the model about the time and circumstances under which individuals decide about their labour market participation being rather strong, we can conclude that individuals who experienced relatively high social benefits in the previous year are unlikely to participate in the labour market in the next year.

The same regression models were performed on data for six selected European countries. Most of them confirmed the expectations, as did the Czech results. Similar negative effect of social benefits on the probability of labour market participation appeared in Poland, less strong but still negative effect was revealed in Italy and Greece, and also in Slovakia in case of the female sub-sample. Moreover, in these countries, the negative effect was even stronger in the female models. On the other hand, Hungary showed rather ambiguous results and Spain proved a positive effect on participation, although the reason could be the very low share of Spanish individuals who received any social benefits at all.

Although the negative effect of social benefits on labour market participation proved in the majority of included countries, the impact in the Czech Republic seems to be relatively strong. Therefore, it might be concluded that the often called "generous" social benefit system in the Czech Republic does create certain work disincentives. 
The upcoming reforms, if effective, could be an appropriate way to stimulate the decreasing labour market participation rate.

\section{References}

Beblo, M., Beninger, D., Heinze, A. and Laisney, F. (2003), "Methodological Issues Related to the Analysis of Gender Gaps in Employment, Earnings and Career Progression". Final Project Report for the European Commission, Employment and Social Affairs DG, Mannheim: ZEW, http:// ec.europa.eu/employment_social/employment_analysis/gender/gender_fin_rep.pdf.

Carone, G., Salomäki, A. (2001), "Reforms in Tax-benefit Systems in order to Increase Employment Incentives in the EU". DG for Economic and Financial Affairs Economic Papers No. 160, Brussels: European Commission.

Carone, G., Immervoll, H., Paturot, D., Salomäki, A. (2004), "Indicators of Unemployment and Low-Wage Traps. Marginal Effective Tax Rates on Employment Incomes". OECD Social, Employment and Migration Working Papers No. 18, Paris: OECD.

Czech Statistical Office (2007a), Income and Living Conditions of Households in CR, 2005. Prague: Czech Statistical Office.

Czech Statistical Office (2007b), Income and Living Conditions of Households in CR, 2006. Prague: Czech Statistical Office.

European Commission (2000), Employment in Europe 2000. Brussels: European Commission.

European Commission (2004), Benefit Systems and Their Interaction with Active Labour Market Policies. Brussels: European Commission.

European Commission (2006), Employment in Europe 2006. Brussels: European Commission.

European Commission (2007), Employment in Europe 2007. Brussels: European Commission.

Heckman, J. (1979), "Sample Selection Bias as a Specification Error". Econometrica, Vol. 47, pp. 153-163.

Hosmer, D. W., Lemeshow, S. (2000), Applied Logistic Regression. $2^{\text {nd }}$ edition, New York: John Wiley \& Sons.

Immervoll, H., O'Donoghue, C. (2003), "Employment Transitions in 13 European Countries: Levels, Distributions and Determining Factors of Net Replacement Rates". Euromod Working Paper No. EM3/03, Colchester: Euromod.

Jaumotte, F. (2003), „Female Labour Force Participation: Past Trends and Main Determinants in OECD Countries". OECD Economics Department Working Papers No. 376, Paris: OECD.

Mysíková, M. (2007), "Gender Wage Gap and Its Determinants", in Večerník, J., ed., Czech Labour Market: Changing Structures and Work Orientations. Sociological Studies No. 4, Prague: Institute of Sociology of the Academy of Sciences.

OECD (1997), Making Work Pay. Taxation, Benefits, Employment and Unemployment. Paris: OECD.

OECD (2002), Benefits and Wages 2002. Paris: OECD.

OECD (2004), OECD Economic Survey of the Czech Republic 2004. Inactivity Traps and Mobility. Paris: OECD.

Renoy, P., Staffan, I., van der Wusten-Gritsai, O., Meijer, E. (2004), Undeclared Work in an Enlarged Union. Brussels: European Commission.

Sandmeyer, R. L., Warner, L. B. (1970), "A Note on the Discouragement Effect". Industrial and Labor Relations Review, Vol. 23, No. 3, pp. 406-413.

Schweitzer, S. O., Smith, R. E. (1974), "The Persistence of the Discouraged Worker Effect". Industrial and Labor Relations Review, Vol. 27, No. 2, pp. 249-260.

Snower, D. J. (1995), "Evaluating Unemployment Policies: What Do the Underlying Theories Tell Us?" IMF Working Paper No. 95/7, Washington: IMF. 


\section{Appendix 1}

Table A.1

Heckman Model

\begin{tabular}{|c|c|c|c|c|c|c|c|}
\hline & $\mathbf{C Z}$ & SK & PL & $\mathbf{H U}^{\mathbf{a}}$ & IT & ES & GR \\
\hline \multicolumn{8}{|c|}{ Wage equation (hourly ln wage) } \\
\hline EDUC_YEARS & $0.040 * * *$ & $0.039 * * *$ & $0.053 * * *$ & $0.095 * * *$ & $0.047 * * *$ & $0.025 * * *$ & $0.030 * * *$ \\
\hline YEARS_WORK & $0.017 * * *$ & $0.012 * * *$ & $0.023 * * *$ & $0.012 * * *$ & $0.031 * * *$ & $0.021 * * *$ & $0.041 * * *$ \\
\hline YEARS_W2 & $-0.000 * * *$ & $-0.000 * * *$ & $-0.000 * * *$ & $-0.000^{*}$ & $-0.001 * * *$ & $-0.000 * * *$ & $-0.001 * * *$ \\
\hline SEX & $0.221 * * *$ & $0.233 * * *$ & $0.095 * * *$ & $0.164 * * *$ & $0.172 * * *$ & $0.196 * * *$ & - \\
\hline REG1 & $0.123 * * *$ & - & $0.128 * * *$ & $0.109^{* * *}$ & - & $0.050^{* *}$ & - \\
\hline REG2 & 0.020 & - & $0.092 * * *$ & $0.033^{*}$ & - & $0.224 * * *$ & - \\
\hline REG3 & -0.027 & - & 0.005 & - & - & $0.104 * * *$ & - \\
\hline REG4 & -0.038 & - & 0.021 & - & - & $0.088 * * *$ & - \\
\hline REG5 & $-0.076 * * *$ & - & $0.095 * * *$ & - & - & $0.117 * * *$ & - \\
\hline REG6 & $-0.080 * * *$ & - & - & - & - & $0.060 * *$ & - \\
\hline REG7 & $-0.102 * * *$ & - & - & - & - & - & - \\
\hline ISCO1 & $0.562 * * *$ & $0.475 * * *$ & $0.672 * * *$ & $0.528 * * *$ & $0.530 * * *$ & $0.558 * * *$ & $0.547 * * *$ \\
\hline ISCO2 & $0.430 * * *$ & $0.430 * * *$ & $0.602 * * *$ & $0.355^{* * *}$ & $0.529 * * *$ & $0.612 * * *$ & $0.643 * * *$ \\
\hline ISCO3 & $0.418 * * *$ & $0.384 * * *$ & $0.426^{* * *}$ & $0.360^{* * *}$ & $0.355^{* * *}$ & $0.344 * * *$ & $0.334 * * *$ \\
\hline ISCO4 & $0.335 * * *$ & $0.280 * * *$ & $0.298 * * *$ & $0.229 * * *$ & $0.261 * * *$ & $0.242 * * *$ & $0.287 * * *$ \\
\hline ISCO5 & $0.086 * * *$ & $0.059 * *$ & $0.039 *$ & 0.007 & $0.164 * * *$ & $0.078 * * *$ & $0.186 * * *$ \\
\hline ISCO6 & 0.027 & 0.086 & 0.093 & -0.072 & 0.058 & -0.006 & $-0.007 * * *$ \\
\hline ISCO7 & $0.200 * * *$ & $0.172 * * *$ & $0.160 * * *$ & $0.093 * * *$ & $0.098 * * *$ & $0.074 * * *$ & $0.154 * * *$ \\
\hline ISCO8 & $0.150 * * *$ & $0.189 * * *$ & $0.193 * * *$ & $0.135 * * *$ & $0.172 * * *$ & $0.112 * * *$ & $0.223 * * *$ \\
\hline ISCO0 & $0.682 * * *$ & - & $0.712 * * *$ & $0.481 * * *$ & $0.469 * * *$ & $0.328 * * *$ & $0.476 * * *$ \\
\hline CONSTANT & $3.195^{* * *}$ & $-0.334 * * *$ & $-0.814 * * *$ & $-0.983 * * *$ & $0.872 * * *$ & $0.956^{* * *}$ & $0.813 * * *$ \\
\hline \multicolumn{8}{|c|}{ Participation equation } \\
\hline UNEARN_INC & $-0.013 * * *$ & $-0.001 * * *$ & $-0.234 * * *$ & $-0.167 * * *$ & $-0.014 * * *$ & $-0.019 *$ & $-0.051 * * *$ \\
\hline AGE_30 & $0.496^{* *}$ & - & $1.171^{* * *}$ & - & $0.986 * * *$ & $1.428 * * *$ & $1.066 * * *$ \\
\hline AGE31_45 & $0.700 * * *$ & - & $1.305^{* * *}$ & $0.423 * * *$ & $0.925 * * *$ & $1.067 * * *$ & $0.946 * * *$ \\
\hline AGE46_55 & 0.440 & - & $0.964 * * *$ & $0.364 * * *$ & $0.751 * * *$ & $0.650 * * *$ & $0.772 * * *$ \\
\hline CHILD0_2 & $-1.583 * * *$ & $-0.358 * * *$ & $-0.588 * * *$ & $-0.651 * * *$ & $-0.391 * * *$ & $-0.365^{* * *}$ & - \\
\hline CHILD3_5 & $-0.871 * * *$ & -0.157 & $-0.225^{* * *}$ & $-0.199 * *$ & $-0.275^{* * *}$ & $-0.303 * * *$ & - \\
\hline CHILD6_16 & - & 0.120 & - & $-0.111 * * *$ & $-0.245^{* * *}$ & $-0.167 * * *$ & - \\
\hline EM_PART & $-0.365^{* * *}$ & - & - & - & $-0.447 * * *$ & $-0.542 * * *$ & $-0.800 * * *$ \\
\hline NEM_PART & - & - & - & - & $-0.329 * * *$ & $-0.357 * * *$ & $-0.901 * * *$ \\
\hline EDUC_SEC & - & - & $0.471^{* * *}$ & $1.275^{* * *}$ & $0.666^{* * *}$ & $0.404 * * *$ & $0.470 * * *$ \\
\hline EDUC_TER & $0.292 *$ & $0.186^{*}$ & $1.335^{* * *}$ & $1.726^{* * *}$ & $1.425^{* * *}$ & $1.326^{* * *}$ & $1.434 * * *$ \\
\hline SEX & $1.504 * * *$ & $0.610 * * *$ & $0.795 * * *$ & $0.733 * * *$ & $1.445^{* * *}$ & $1.959 * * *$ & $2.148 * * *$ \\
\hline CONSTANT & $1.579 * * *$ & $1.723 * * *$ & $-0.720 * * *$ & -0.454 & $-0.609 * * *$ & $-0.505^{* * *}$ & $-0.241 *$ \\
\hline RHO & 0.445 & -0.153 & -0.273 & 0.701 & 0.479 & 0.271 & -0.519 \\
\hline SIGMA & 0.296 & 0.359 & 0.485 & 0.467 & 0.350 & 0.347 & 0.348 \\
\hline Wald (chi2, 1) & 5.57 & 6.12 & 14.59 & 38.63 & 62.98 & 5.81 & 39.38 \\
\hline Prob > chi 2 & 0.018 & 0.013 & 0.000 & 0.000 & 0.000 & 0.016 & 0.000 \\
\hline
\end{tabular}

Notes: * significance at the $10 \%$ level, ${ }^{* *}$ significance at the $5 \%$ level, ${ }^{* * *}$ significance at the $1 \%$ level.

a) Data on number of worked years is missing in Hungary; AGE - EDUC YEARS - 6 applied instead.

Source: Own calculations based on EU-SILC data. 


\section{Appendix 2}

Table A. 2

Descriptive Summary - Weighted

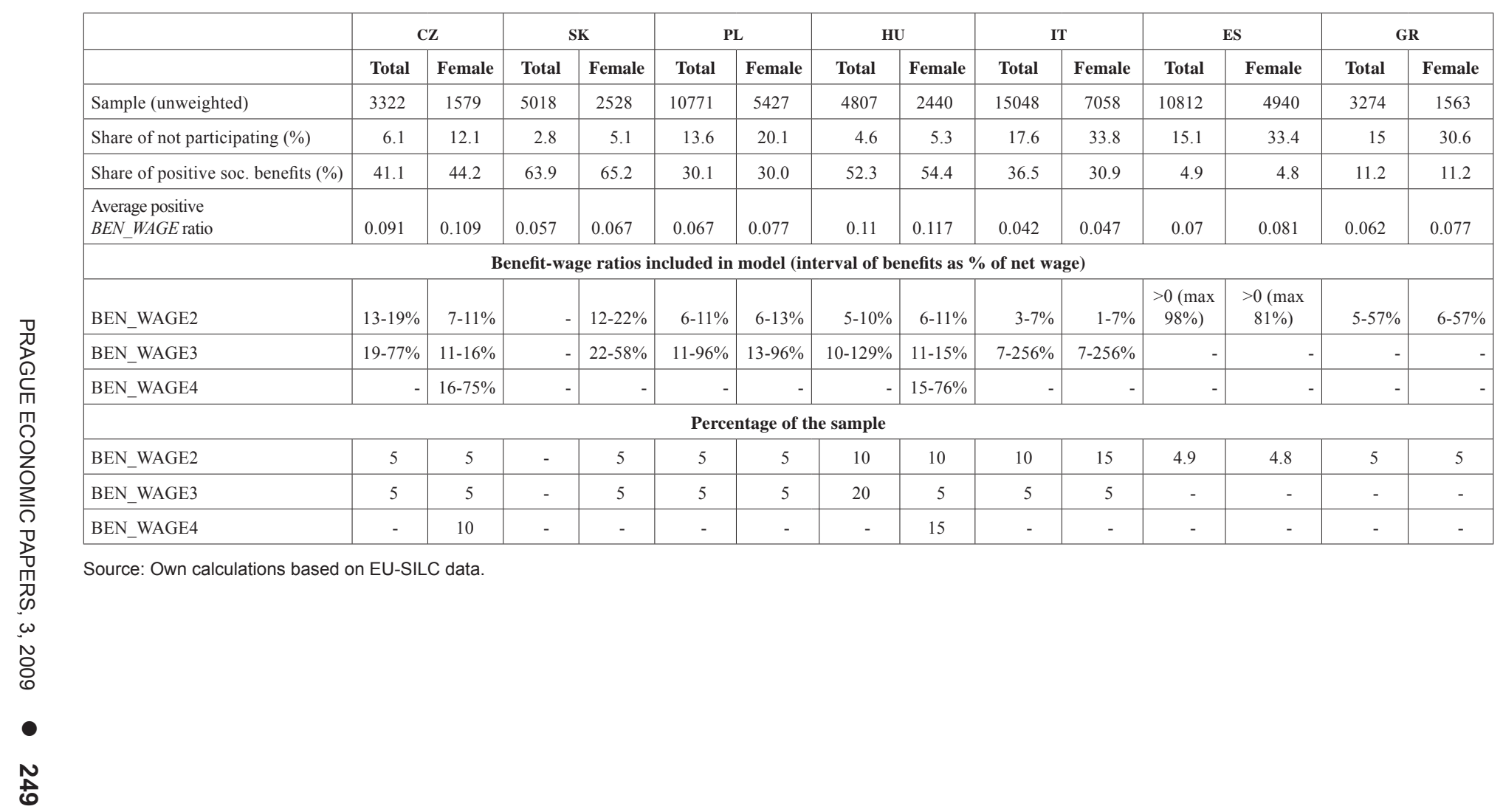




\section{ज్ Appendix 3 \\ Table A.3}

- Participation Model - Odds Ratio

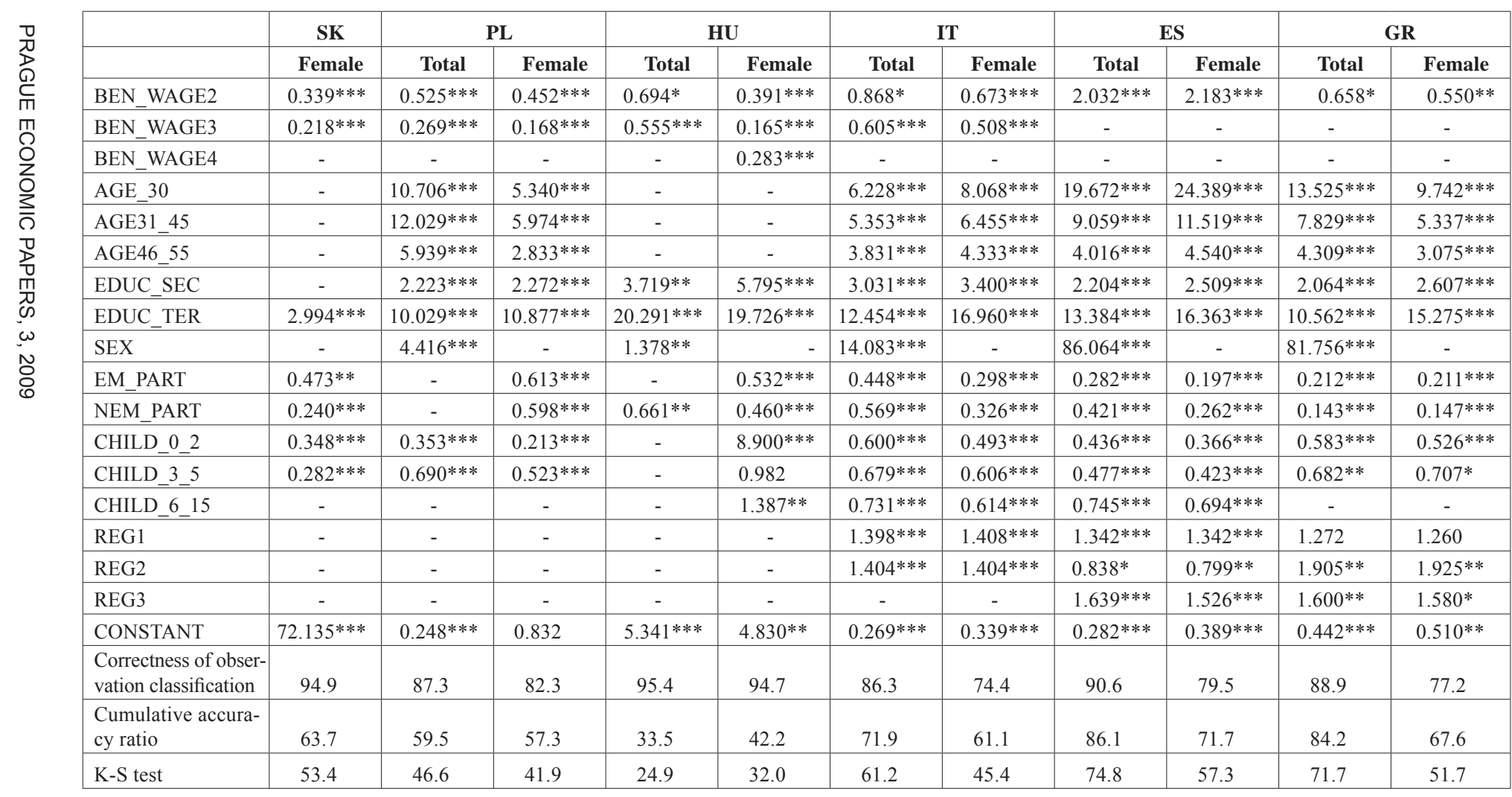

Notes: * significance at the $10 \%$ level, ${ }^{* *}$ significance at the $5 \%$ level, ${ }^{* * *}$ significance at the $1 \%$ level.

Source: Own calculations based on EU-SILC data. 